University of Nebraska - Lincoln

DigitalCommons@University of Nebraska - Lincoln

$11-2008$

\title{
Toward Using National Cancer Surveillance Data for Preventing and Controlling Cervical and Other Human Papillomavirus- associated Cancers in the US
}

\author{
Mona Saraiya \\ Centers for Disease Control and Prevention, msaraiya@cdc.gov \\ Faruque Ahmed \\ Centers for Disease Control and Prevention, fahmed@cdc.gov \\ Mary White \\ Centers for Disease Control and Prevention, mary.white@nursing.ucsf.edu \\ Herschel Lawson \\ Centers for Disease Control and Prevention \\ Elizabeth R. Unger \\ Centers for Disease Control and Prevention, eunger@cdc.gov \\ See next page for additional authors
}

Follow this and additional works at: https://digitalcommons.unl.edu/publichealthresources

Part of the Public Health Commons

Saraiya, Mona; Ahmed, Faruque; White, Mary; Lawson, Herschel; Unger, Elizabeth R.; and Eheman, Christie, "Toward Using National Cancer Surveillance Data for Preventing and Controlling Cervical and Other Human Papillomavirus-associated Cancers in the US" (2008). Public Health Resources. 269.

https://digitalcommons.unl.edu/publichealthresources/269

This Article is brought to you for free and open access by the Public Health Resources at DigitalCommons@University of Nebraska - Lincoln. It has been accepted for inclusion in Public Health Resources by an authorized administrator of DigitalCommons@University of Nebraska - Lincoln. 


\section{Authors}

Mona Saraiya, Faruque Ahmed, Mary White, Herschel Lawson, Elizabeth R. Unger, and Christie Eheman 


\section{Assessing the Burden of HPV-Associated Cancers in the United States}

Supplement to Cancer

\section{Toward Using National Cancer Surveillance Data for Preventing and Controlling Cervical and Other Human Papillomavirus-associated Cancers in the US}

\author{
Mona Saraiya, MD, MPH ${ }^{1}$ \\ Faruque Ahmed, PhD ${ }^{1,2}$ \\ Mary White, $\mathrm{ScD}^{1}$ \\ Herschel Lawson, mD ${ }^{1}$ \\ Elizabeth R. Unger, $\mathrm{MD}, \mathrm{PhD}^{3}$ \\ Christie Eheman, PhD ${ }^{1}$ \\ ${ }^{1}$ Division of Cancer Prevention and Control, Cen- \\ ters for Disease Control and Prevention, Atlanta, \\ Georgia. \\ ${ }^{2}$ Immunization Services Division, Centers for \\ Disease Control and Prevention, Atlanta, Georgia. \\ ${ }^{3}$ Division of Viral and Rickettsial Diseases, Cen- \\ ters for Disease Control and Prevention, Atlanta, \\ Georgia.
}

Funded by the Centers for Disease Control and Prevention.

This supplement to CANCER was supported by Cooperative Agreement Number U50 DP42407104 from the Centers for Disease Control and Prevention (CDC).

Dr. Ahmed was formerly with the Division of Cancer Prevention and Control at the Centers for Disease Control and Prevention, Atlanta, Georgia.

The following registries, which cover approximately $83 \%$ of the US population, contributed data to the production of this supplement: Alaska, Alabama, Arkansas, California, Colorado, Connecticut, District of Columbia, Delaware, Florida, Hawaii, Idaho, Illinois, Indiana, lowa, Kansas, Kentucky, Louisiana, Maine, Massachusetts, Michigan, Minnesota, Missouri, Montana, Nebraska, New Jersey, New Mexico, New York, Ohio, Oklahoma, Oregon, Pennsylvania, Rhode Island, South Carolina, Texas, Utah, Vermont, Washington, West Virginia, and Wisconsin.
$\mathbf{T}$ his supplement, known as the ABHACUS (Assessing the Burden of HPV-Associated Cancers in the United States) supplement, contains 22 articles. Together, these articles provide a comprehensive snapshot of data related to the occurrence and control of multiple cancers that have been associated with the human papillomavirus (HPV). These analyses highlight the burden of HPVassociated cancers in the US population as a whole and among vulnerable population subgroups. We anticipate that these findings will be an important resource for enhancing existing strategies for the prevention and control of HPV-associated cancers.

HPV is estimated to be responsible for $5.2 \%$ of the cancers diagnosed worldwide. ${ }^{1}$ Virtually $100 \%$ of cervical cancers are causally associated with HPV, and there is increasing evidence of the role that HPV plays in other anogenital cancers and oropharyngeal cancers. With the recent approval and recommendation of an HPV vaccine that contains HPV-16 and HPV-18, interest in quantifying the
We appreciate the in-kind support from all the contributors to this supplement. We are also grateful for the guidance provided by the project steering committee members: Faruque Ahmed, Umed Ajani, Janet Bates, Apputhurai Balamuragan, Vicki Benard, Cheryll Cardinez, Vivien Chen, Glenn Copeland, Michelle Cote, Steve Coughlin, Eileen Dunne, Donatus Ekwueme, Brenda Edwards, Anna Giuliano, Brenda Hernandez, Claudia Hopehayn, Djenaba Joseph, Kris Khan, Jessica King, Sue-Min Lai, Herschel Lawson, Serban Negoita, Marsha Reichman, Tom Richards, Blythe Ryerson, Mona Saraiya, Trevor Thompson, Jasmin Tiro, Meg Watson, Hannah Weir, Mary White, Martin Whiteside, Phyllis Wingo, and Xiao-Cheng Wu. Our gratitude also goes to our team of pathologists, Diane Solomon, Beth Unger, and Mark Sherman; to editorial and graphic services at the Centers for Disease Control and Prevention, especially Fonda Martin, Ernest Martin, and Rick Hull; to Dave Stinchcomb for creating maps; to Jessica King, Trevor Thompson, and Kevin Zhang for the creation of the analytic files and for data verification; to the publication committee (Tom Richards, Mona Saraiya, Phyllis Wingo, and Meg Watson); and to the leadership of the Centers for Disease Control and Prevention's Division of Cancer Prevention and Control for support of this project (Barbara Bowman and Robert German).

The findings and conclusions in this report are those of the authors and do not necessarily represent the views of the Centers for Disease Control and Prevention.

Address for reprints: Mona Saraiya, MD, MPH, Division of Cancer Prevention and Control, Centers for Disease Control and Prevention, 4770 Buford Highway NE, MS K-55, Atlanta, GA 30341; Fax: (770) 488-4639; E-mail: msaraiya@cdc.gov

Received April 14, 2008; accepted April 22, 2008.

*This article is a US Government work and, as such, is in the public domain in the United States of America. 
spectrum and burden of cancers is heightened. The International Agency for Research on Cancer (IARC) has determined that there is sufficient evidence for the carcinogenicity of HPV-16 in the cervix, vulva, vagina, penis, anus, oral cavity, and oropharynx. ${ }^{2}$ The IARC has found sufficient evidence of the role HPV-18 plays in cervical cancer, with limited or no evidence in other sites. Together, cervical cancer combined with the other HPV-associated cancers potentially afflicts an additional 25,000 persons every year in the US.

Worldwide and in the US, the excitement and concern surrounding the HPV vaccine has been profound. The excitement derives from the potential of the vaccine to reduce the burden of cervical cancer in countries that have no screening infrastructure as well as in countries such as the US, in which nearly 11,000 women each year are told they have invasive cervical cancer and 4000 die from this disease, despite the availability of screening. The HPV vaccine also has the potential to impact a significant proportion of other cancers for which there typically is no routine screening. Conversely, the concern is that vaccine recipients may not continue to undergo screening for cervical cancer. Yet another concern is that if vaccine uptake is lower in those groups at highest risk of developing cervical cancer, current $\mathrm{racial} / \mathrm{ethnic}$ or geographic disparities could increase. We hope that the articles in this supplement will highlight the burden and disparities associated with these cancers before vaccine implementation.

This supplement includes an in-depth analysis of cancer incidence and mortality data from population-based central cancer registries that house highquality data. Fourteen articles are based mainly on cancer occurrence, using incidence data from population-based central cancer registries that participate in the Centers for Disease Control and Prevention (CDC)'s National Program of Cancer Registries (NPCR) and/or the National Cancer Institute (NCI)'s Surveillance, Epidemiology, and End Results (SEER) program. The NPCR program, which was established through the Cancer Registries Amendment Act passed by the US Congress in 1992, began providing financial support and technical assistance to population-based central cancer registries in 1994. This program currently supports central registries in 45 states, the District of Columbia, and 3 US territories; these registries cover approximately $96 \%$ of the US population. The SEER program, which was established as a result of the National Cancer Act of 1971, currently supports 14 such registries and 3 supplemental registries, covering approximately $26 \%$ of the US population. The population-based central cancer registries collect information on all reportable cancer cases within a state or another defined geographic area. Today, the NPCR and SEER programs together cover $100 \%$ of the US population, and data regarding more than 1 million new invasive cancer cases are added each year. Medical records are the primary source of the data. Both the NPCR and SEER data are collected and reported with the use of uniform data items and codes, as documented by the North American Association of Central Cancer Registries. ${ }^{3}$ The Institute of Medicine has recognized the importance of these 2 programs as valuable resources for studies on cancer. ${ }^{4}$

National and regional population coverage of cancer registry data has been achieved only within the last few years. Such coverage now allows for the unprecedented examination of rare cancers, as well as a focus on cancer burden by age, sex, race, histology, geography, and other variables. This supplement leverages US population-based cancer registries by demonstrating the current burden of disease for all 6 HPV-associated cancers in each of the individual site-specific chapters (cervical, vaginal, vulvar, anal, penile, and oropharyngeal cancers) ${ }^{5-10}$ Before engaging in any analyses, the steering committee spent a considerable amount of time establishing common definitions. Watson et al describe the registries in more detail and provide some standardized analytic criteria used in the site-specific analyses. ${ }^{11}$ Benard et al highlight some of the applications of cancer registry data, augmented with linked census-based socioeconomic data, thereby to our knowledge underscoring for the first time general patterns that are observed for each of the HPV-associated cancers. ${ }^{12}$ Ryerson et al focus on the HPV-associated cancer burden for oral cavity and oropharyngeal cancers, using anatomic subsites as a proxy for HPV association. ${ }^{5}$

Several articles take advantage of the unique attributes of certain central cancer registries or go beyond the description of cancer occurrence. For example, data from the California Cancer Registry allow for the computation of cancer incidence rates for Asian subpopulations, some of which have been known to have the highest incidence of cervical cancer in the US. ${ }^{13}$ Despite the 1996 recommendation to discontinue the collection of data regarding carcinoma in situ (CIS) of the cervix, the Michigan Cancer Surveillance System continued to collect these data; Copeland et al present current trends related to cervical CIS. ${ }^{14}$ Hopehayn et al and Coughlin et al examine the burden of cervical cancer in areas with disproportionate burdens: Appalachia and those states bordering Mexico. ${ }^{15,16}$ Additional articles use 
cancer registry data to examine treatment patterns for female HPV-associated cancers and the risk of other HPV-associated cancers among cervical cancer survivors. ${ }^{17}$ Finally, an examination of the years of potential life lost and mortality-related productivity costs of all HPV-associated cancers is presented. ${ }^{18}$

Because of the importance of primary prevention and screening for cancer control, another aim of this supplement is to update the reader with pertinent information related to vaccination and screening. Dunne et al describe the epidemiology of HPV and the HPV vaccine. ${ }^{19}$ Tiro et al examine various national behavioral surveillance systems related to cervical cancer screening and vaccination. ${ }^{20}$ Castle et al comment on the potential impact of the HPV vaccine on cervical cancer screening in the years to come. ${ }^{21}$ Whiteside et al present an overview of what is known concerning the molecular mechanisms involved in HPV oncogenesis to help readers interpret data regarding HPV causality in noncervical cancers and understand the new molecular markers proposed for screening. ${ }^{22}$ Gillison et al discuss the role of HPV in noncervical cancers and apply worldwide and US estimates of attributable fractions to further define the burden of HPV-associated cancers. ${ }^{22}$ Another article comments on the role the cancer registries can play in monitoring the impact of the HPV vaccine. ${ }^{23}$ Lastly, Khan et al describe 2 key CDC programs related to cervical cancer prevention (the Vaccines for Children Program) and screening (the National Breast and Cervical Cancer Early Detection Program) that target uninsured individuals and other vulnerable populations. ${ }^{24}$

A few years ago, the National Coordinating Council for Cancer Surveillance developed a national framework for cancer surveillance in the US. ${ }^{25}$ This supplement represents the application of this cancer surveillance framework to HPV-associated cancers. To be effective, cancer surveillance requires coordination and cooperation among government, professional, nonprofit, and private organizations, and the articles contained in this supplement demonstrate the success that can be achieved through such collective efforts. Greater than 100 investigators and 30 peer reviewers from various divisions at the CDC, various parts of the NCI, population-based cancer registries (Arkansas, Arizona, California, Florida, Idaho, Illinois, Kansas, Kentucky, Louisiana, Maine, Michigan, New Mexico, New York, South Dakota, Tennessee, Texas, and Washington DC), academic institutions, and the American Cancer Society worked diligently and collaboratively over the past year and a half to produce this supplement. We wish to express our deepest gratitude to them.

\section{REFERENCES}

1. Parkin DM. The global health burden of infection-associated cancers in the year 2002. Int J Cancer. 2006;118: 3030-3044.

2. Cogliano V. IARC Monographs on the Evaluation of Carcinogenic Risks to Humans: Human Papillomavirus. Lyon, France: International Agency for Research on Cancer; 2007.

3. Wingo PA, Jamison PM, Hiatt RA, et al. Building the infrastructure for nationwide cancer surveillance and control-a comparison between the National Program of Cancer Registries (NPCR) and the Surveillance, Epidemiology, and End Results (SEER) Program (United States). Cancer Causes Control. 2003;14:175-193.

4. Institute of Medicine (IOM) National Research Council and National Cancer Policy Board. Enhancing Data Systems to Improve the Quality of Cancer Care. Washington, DC: The National Academies Press; 2000.

5. Ryerson AB, Peters ES, Coughlin SS, et al. Burden of potentially HPV-associated cancers of the oropharynx and oral cavity in the US, 1998-2003. Cancer. 2008;113(10 suppl): 2901-2909

6. Joseph DA, Miller JW, Wu X, et al. Understanding the burden of HPV-associated anal cancers in the United States. Cancer. 2008;113(10 suppl):2892-2900.

7. Saraiya M, Watson $\mathrm{M}, \mathrm{Wu} \mathrm{X}$, et al. Incidence of in situ and invasive vulvar cancer in the United States, 1998-2003. Cancer. 2008;113(10 suppl):2865-2872.

8. Wu X, Matanoski G, Chen VW, et al. Descriptive epidemiology of vaginal cancer incidence and survival by race, ethnicity, and age in the United States. Cancer. 2008;113 (10 suppl):2873-2882.

9. Hernandez BY, Barnholtz-Sloan J, German RR, et al. Burden of penile cancer in the United States. Cancer. 2008; 113(10 suppl):2883-2891.

10. Watson M, Saraiya M, Benard V, et al. Burden of cervical cancer in the United States, 1998-2003. Cancer. 2008; 113(10 suppl):2855-2864.

11. Watson M, Saraiya M, Ahmed F, et al. Using populationbased cancer registry data to assess the burden of HPVassociated cancers in the US: overview of methods. Cancer. 2008;113(10 suppl):2841-2854.

12. Benard VB, Johnson CJ, Thompson TD, et al. Examining the association between socioeconomic factors and human papillomavirus-related cancers. Cancer. 2008;113(10 suppl): 2910-2918.

13. Bates JH, Parikh-Patel A, Hofer BM. Cervical cancer incidence, mortality, and survival among Asian subgroups in California, 1988-2004. Cancer. 2008;113(10 suppl):2955-2963.

14. Copeland G, Datta SD, Spivak G, Garvin AD, Cote M. Total burden and incidence of in situ and invasive cervical cancer in Michigan, 1985-2003. Cancer. 2008;113(10 suppl): 2946-2954.

15. Hopenhayn C, King JB, Christian A, Huang B, Christian WJ. Variability of cervical cancer rates across 5 Appalachian states, 1998-2003. Cancer. 2008;113(10 suppl):2974-2980.

16. Coughlin SS, Richards TB, Nasseri K, et al. Cervical cancer incidence in the US-Mexico border region, 1998-2003. Cancer. 2008;113(10 suppl):2964-2973.

17. Balamurugan A, Ahmed F, Saraiya M, et al. Potential role of human papillomavirus in the development of subsequent primary in situ and invasive cancers among cervical cancer survivors. Cancer. 2008;113(10 suppl):2919-2925.

18. Ekwueme DU, Chesson HW, Zhang KB, Balamurugan A. Years of potential life lost and lost productivity costs 
due to HPV-associated cancer and all malignant cancer mortality in the United States, 2003. Cancer. 2008;113 (10 suppl):2936-2945.

19. Dunne EF, Datta SD, Markowitz L. Overview of prophylactic HPV vaccines in the United States. Cancer. 2008;113(10 suppl):2995-3003.

20. Tiro JA, Saraiya M, Jain N, et al. HPV and cervical cancer behavioral surveillance in the US. Cancer. 2008;113(10 suppl):3013-3030.

21. Castle P, Solomon D, Saslow D, Schiffman M. Predicting the effect of successful HPV vaccination on existing U.S. cervical screening programs. Cancer. 2008;113(10 suppl): 3031-3035.
22. Gillison ML, Chaturvedi AK, Lowy DR. HPV prophylactic vaccines and the potential prevention of non-cervical cancers in both men and women. Cancer. 2008;113(10 suppl):3036-3046.

23. Saraiya M, Goodman MT, Datta SD, Chen VW, Wingo P. Cancer registries and monitoring the impact of prophylactic HPV vaccines: potential role. Cancer. 2008;113(10 suppl):3047-3057.

24. Khan K, Curtis CR, Ekwueme DU, et al. Complementary federal programs for cervical cancer prevention: NBCCEDP, VFC, and 317. Cancer. 2008;113(10 suppl):3004-3012.

25. Wingo PA, Howe HL, Thun MJ, et al. A national framework for cancer surveillance in the United States. Cancer Causes Control. 2005;16:151-170. 